\title{
Patent Foramen Ovale Closure using Cardioform Occluder Device Through the Right Internal Jugular Vein for Primary Prevention (First in Man): Importance of a Multidisciplinary Team
}

\author{
Jad Al Danaf, MD, MPH*, Abdulfattah Saidi, MD, Brigham Smith, MD, Anwar Tandar, MD \\ Division of Cardiovascular Medicine, Department of Internal Medicine, University of Utah, Salt Lake City, Utah, USA
}

\begin{abstract}
Percutaneous transcatheter closure of Patent Foramen Ovale (PFO) is usually performed via the femoral vein but in certain circumstances this approach may not be possible necessitating the need for an alternative access. The right internal jugular vein has been successfully utilized in these cases. We are presenting the first successful PFO closure using a Cardioform Occluder Device to close a PFO as a primary prevention approach in a patient with a large inferior vena cava thrombus from renal cell carcinoma.
\end{abstract}

Copyright $\odot 2019$ Science International Corp.

\section{Key Words}

PFO - Peri-operative risk • IVC thrombus - Cardioform device • Right internal jugular vein • Primary prevention - Multidisciplinary approach

\section{Introduction}

Transcatheter closure of patent foramen ovale (PFO) is a standard and growing procedure at many health care centers. Recently, three promising randomized clinical trials: CLOSE [1], Gore REDUCE [2] and RESPECT [3]; and an updated meta-analysis [4] support PFO closure in patients with cryptogenic stroke compared to medical therapy advocating for an update to the current guidelines. In addition, there are still no primary prevention recommendations for PFO closure. The procedure is usually easily performed with a trans-femoral venous approach given the anatomy of the inferior vena cava (IVC) and the interatrial septum (IAS). However, certain conditions such as an IVC thrombus as in our case may preclude using this access, hence the need for alternative approach such as via the right internal jugular vein (R-IJ).

PFO closure using the R-IJ vein has been successfully reported in several case reports using different occluder devices such as a 25-mm Multi-fenestrated ASD occluder [5] and a Figula Flex II PFO 23/25 mm occluder device [6].

We present the first case to the best of our knowledge of closing a PFO using a $30 \mathrm{~mm}$ Cardioform Occluder Device (COD) from the R-IJ vein in a patient without a history of stroke with an IVC thrombus from renal cell carcinoma (RCC).

Patients with RCC and IVC tumor related thrombus have poor prognosis and radical nephrectomy with thrombectomy is considered to be potentially curative [6]. In our case, the patient had a PFO (Figure 1) and symptomatic severe AS that increased her surgical risk of major adverse cardiovascular events and death.

* Corresponding Author:

Jad AI Danaf, MD, MPH

Division of Cardiovascular Medicine, Department of Internal Medicine University of Utah

30 N. 1900E, Room 4A100, Salt Lake City, UT 84112, USA

Tel.: +1 801587 2451; Fax: +1 801581 7735; E-Mail: jad.aldanaf@hsc.utah.edu 


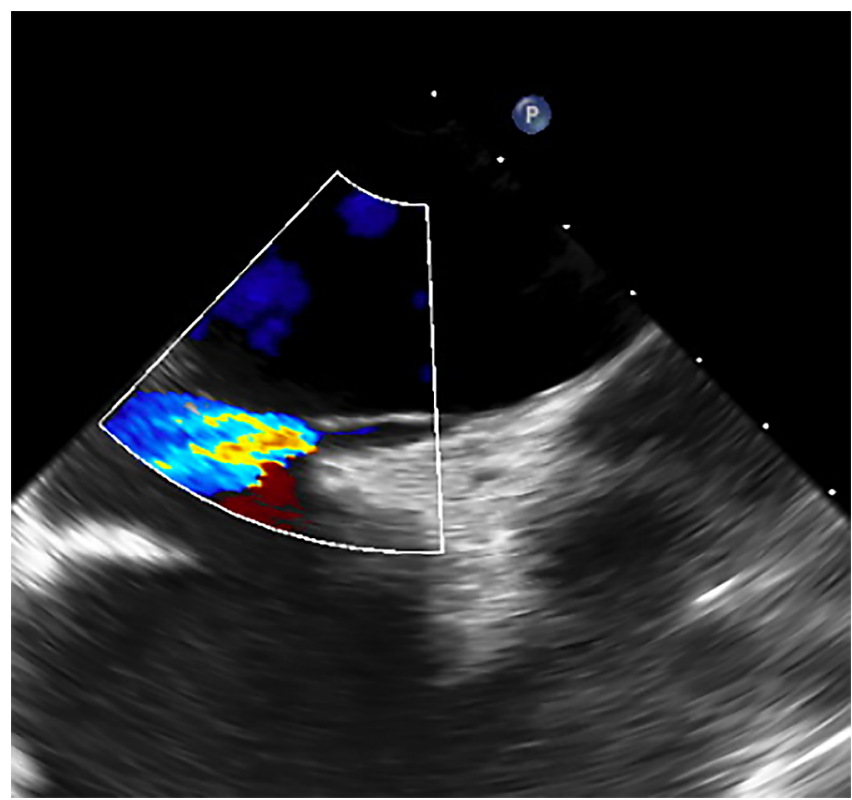

Figure 1. Transesophageal Echocardiogram of the patent foramen ovale with color doppler.

\section{Case presentation}

A 65-year-old woman with stage T3bN1M0 RCC was seen in the structural cardiology clinic as a con- sultation regarding the management of her PFO and severe AS before the surgical resection of the recently discovered left RCC with an extensive IVC tumor-related thrombus (Figure 2). Due to the high intraoperative risk of clot embolization causing a stroke via the PFO and the high surgical risk given her severe AS, it was decided to proceed with PFO closure and aortic valve replacement (AVR) before her radical nephrectomy. She was evaluated by our heart team and deemed high risk for surgical AVR, hence Transcatheter Aortic Valve Replacement (TAVR) was recommended for the treatment of her aortic stenosis.

\section{The procedure}

\section{$R$-IJ vein approach PFO Closure using $30 \mathrm{~mm}$ Cardio-} form Occluder Device

General anesthesia was utilized in this procedure due to the need for transesophageal echocardiography (TEE). A 6Fr sheath was inserted into the RIJ and hemodynamic measurement was obtained showing the following hemodynamics: Right atrial (RA) pressure $=12 \mathrm{mmHg}$, systolic pulmonary artery pressure $=33 \mathrm{mmHg}$ with a mean of $24 \mathrm{mmHg}$, post-capillary wedge pressure $=17 \mathrm{mmHg}$, estimated cardiac
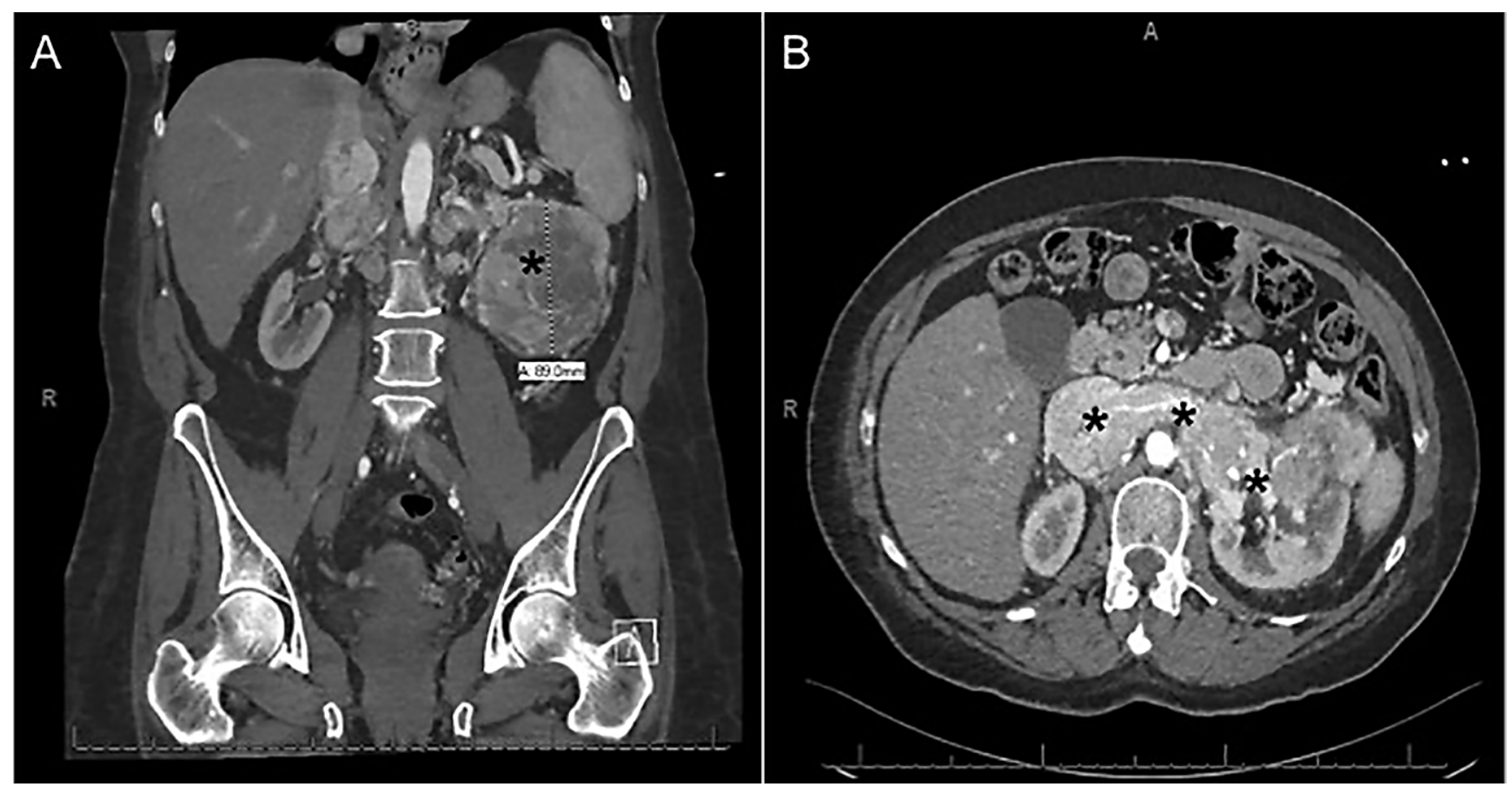

Figure 2. Computerized tomography images of the left renal mass (Panel $A$ ) and thrombus (Panel $B$ ) extending through the left renal vein into the inferior vena cava (IVC). *: Indicates the renal mass and thrombus extending into the IVC. 


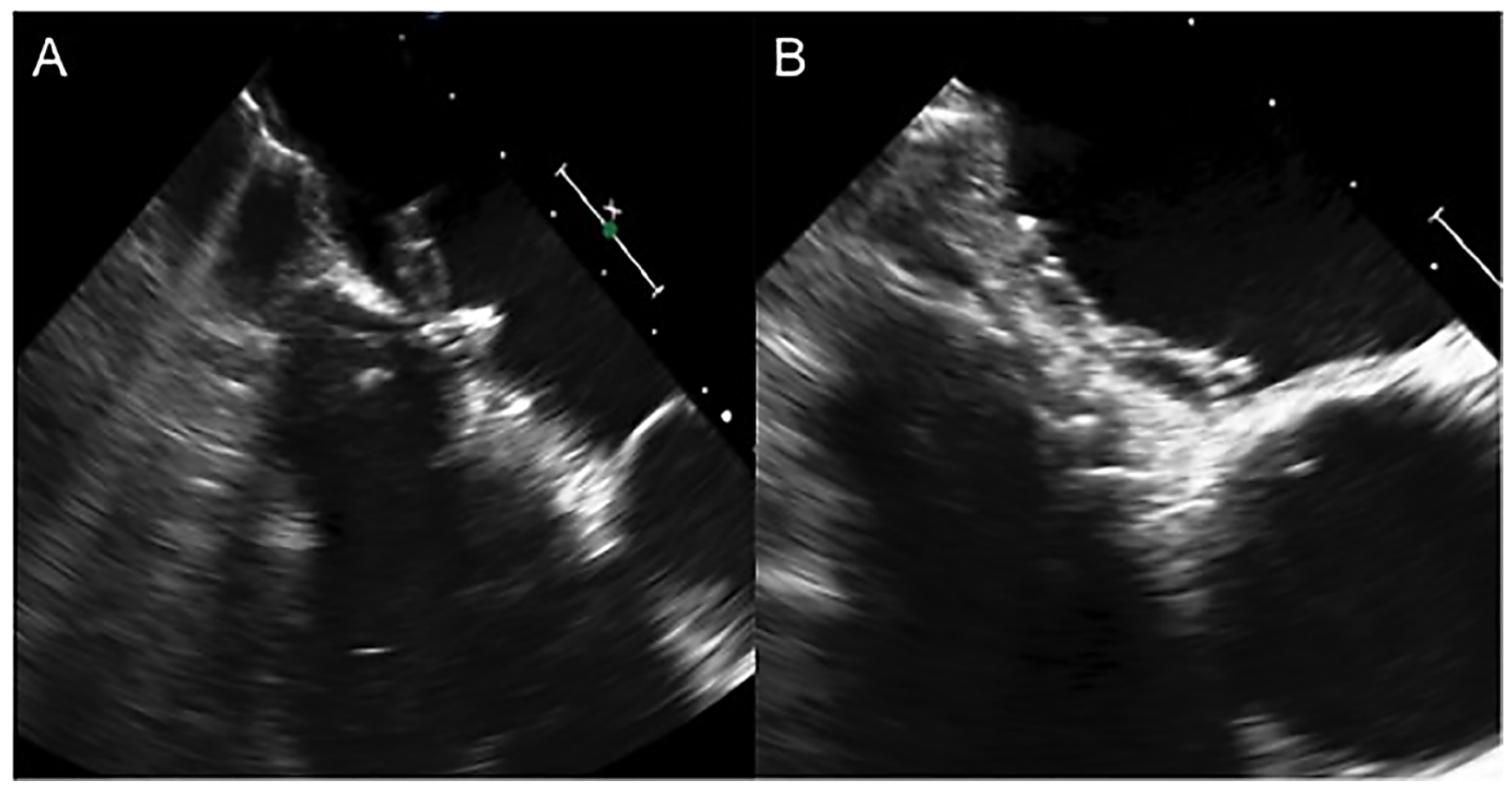

Figure 3. Transesophageal echocardiogram of Cardioform Deployment via right internal jugular vein (Panel A). Transesophageal echocardiogram of full Cardioform Deployment (Panel B).

output by Fick of $6.87 \mathrm{~L} / \mathrm{min}$ and a left atrial pressure of $8 \mathrm{mmHg}$.

An IMA catheter was advanced over a J-wire into the right atrium and the J-wire was then exchanged to an angle glidewire (Terumo ${ }^{\oplus}$, Somerset, NJ). Under fluoroscopic and TEE guidance, the PFO was crossed with some difficulty using the glidewire into the left pulmonary vein. The IMA catheter was then exchanged to a $4 \mathrm{Fr}$ glide catheter (Terumo ${ }^{\circledR}$ ) across the PFO tunnel into the pulmonary vein. The glidewire was then exchanged to a $300 \mathrm{~cm} 0.014$ mailman guide wire (Boston Scientific, Marlborough, MA) and using the manipulation of the glide catheter, the wire was directed into the LV for better support and favorable angulation. The mailman wire was exchanged to Extrastiff $260 \mathrm{~cm} 0.038$ Amplatzer wire (Cook Medical, Bloomington, IN). The glide catheter was removed carefully under fluoroscopic guidance. The Cardioform occluder was chosen because it is felt to have less risk of erosion and less rigidity to accommodate the anatomy as well as the delivery of the occluder. Due to the angulation, it was decided to use the $9 \mathrm{Fr}$
AGA Amplatzer Occluder deliver system (St. Jude Medical-St. Paul, MN) with modification to accommodate the Cardioform optimum delivery. The $30 \mathrm{~mm}$ Cardioform (WL. Gore Medical) was prepped in the usual manner and after carefully removing it from the delivery system; it was carefully advanced over into the LV via customized Amplatzer delivery system. Under fluoroscopic and TEE guidance, the cardioform was advanced and deployed across the PFO with excellent results (Figure 3a and Figure 3b). TEE showed successful closure of the PFO without shunt by color doppler (Figure 4). The cardioform was released and locking mechanism was confirmed (Figure 5). Several bubble saline injections were completed without signs of a residual shunt.

Three days later, she successfully underwent a minimal approach trans-femoral transcatheter aortic valve replacement (TF-TAVR) using a $23 \mathrm{~mm}$ Sapien S3 valve (Edwards LifeScience) that was followed by her radical nephrectomy 5 days later with excellent result. During the 3 months follow up, she continues to do well. 


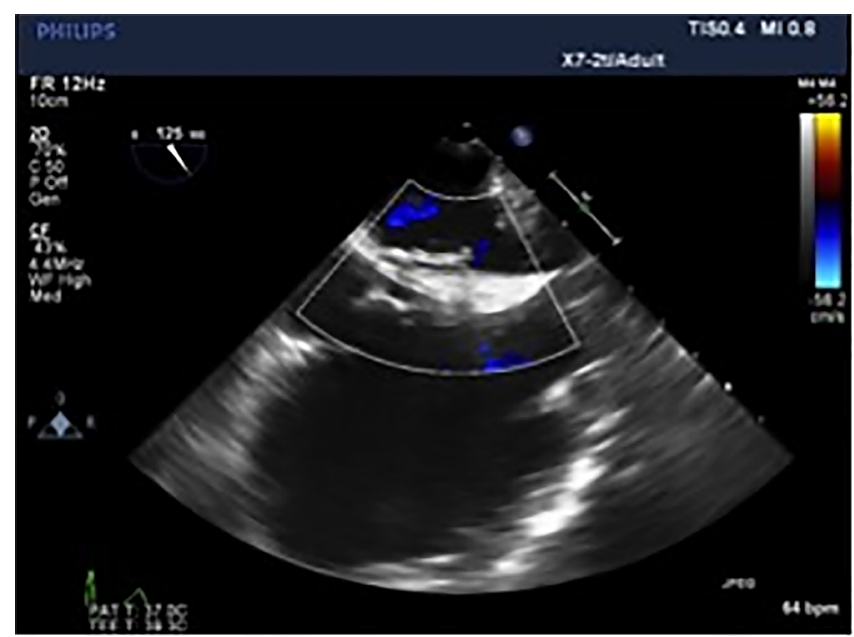

Figure 4. Transesophageal echocardiogram of the Cardioform device with color Doppler..

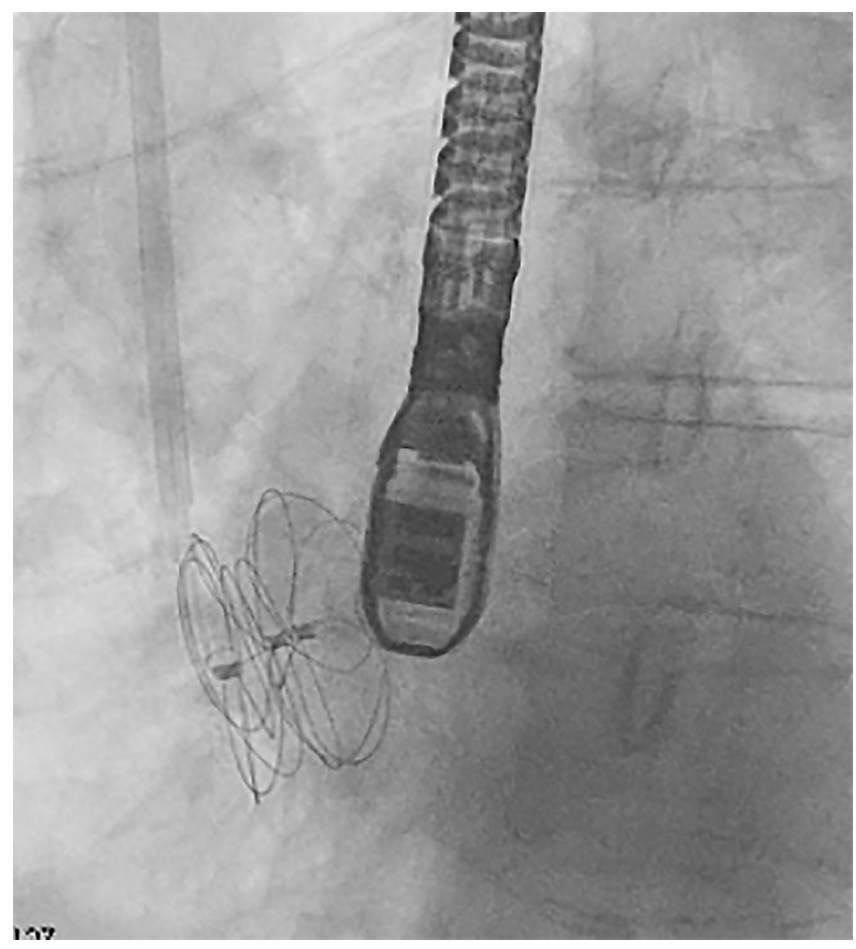

Figure 5. Radiographic image of Cardioform with transesophageal probe.

\section{Discussion}

Given the poor prognosis of patients with extended tumor thrombus from a renal cell carcinoma into the IVC, with rare yet potentially fatal risks of distal embolism particularly intraoperative, the diagnosis of RCC with IVC thrombus necessitates prompt eval- uation and preoperative optimization [7]. Patients in that category with a PFO further warrant rapid coordination of a multidisciplinary team including structural interventional cardiologists to prepare appropriately selected patients for PFO closure before surgical resection of the RCC. Radical nephrectomy with IVC thrombectomy is considered to be the most effective therapeutic option in these patients [7].

The presence of severe AS in patients undergoing non-cardiac surgery (NCS) is often under-recognized and most available preoperative risk calculators do not account for it. The current American [6] and European [10] guidelines recommend AVR for patients with symptomatic severe AS; hence such patients' NCS should ideally be delayed. In our patient, given the time sensitivity of her RCC with an IVC thrombus, along with a very high risk of distal embolization with surgery, we decided to proceed with TAVR to better optimize her cardiovascular risk profile for higher chances of a cardiovascular event free radical nephrectomy.

In our case, decision had to be made with regards to her PFO and severe symptomatic AS in a patient with RCC and an extensive IVC thrombus as a means of optimization for her potentially curative radical nephrectomy. Due to thrombosis of the IVC, and successful case reports of using the R-IJ as the approach for PFO closure, we committed to using that approach. We chose the COD due to a lower erosion risk and ease of its delivery system manipulation given the curved anatomy through the internal jugular vein.

Furthermore, the use of multidisciplinary in-hospital teams has been shown to improve outcomes and improve patient satisfaction [11]. Our extensive discussions and detailed planning with the patient and her family, the team of oncologists, urologists, nephrologists, general surgeons, intensivists and nurses led to successful PFO closure and TAVR that optimized our patient for her curative radical nephrectomy and IVC thrombectomy.

\section{Conclusion}

To the best of our knowledge, this is the first case report of a successful transcatheter PFO closure with a COD through the R-IJ vein. It was also performed 
as a primary prevention of embolic stroke in the setting of a known IVC thrombus in a patient with RCC before radical nephrectomy. This case illustrates the complexity and the significance of proper planning and multidisciplinary discussion to provide the best treatment and care plan particularly in patients with a PFO and symptomatic severe AS.

This is an important viable approach particularly in tertiary and quaternary referral centers that take care of similar cases for optimizing patients with malignancy for major potentially curative surgeries given that about $25 \%$ of the US population has a PFO [12].

\section{Acknowledgement}

The authors would like to acknowledge Dr. Jen Chang from the Department of Anesthesiology at the University of Utah for providing her care during the PFO closure procedure along with TEE guidance.

\section{Conflict of Interest}

The authors have no conflict of interest relevant to this publication.

\section{Comment on this Article or Ask a Question}

\section{References}

1. Mas JL, Derumeaux G, Guillon B, Massardier $E$, Hosseini $H$, Mechtouff $L$, et al. CLOSE Investigators. Patent foramen ovale closure or anticoagulation vs. antiplatelets after stroke. N Engl J Med. 2017;377:10111021. DOI: $10.1056 /$ NEJMoa1705915.

2. Søndergaard L, Kasner SE, Rhodes JF, Andersen G, Helle K. Iversen HK, Nielsen-Kudsk JE, et al. Patent foramen ovale closure or antiplatelet therapy for cryptogenic stroke. N Engl J Med. 2017;377:1033-1042. DOI: 10.1056/NEJMoa1707404.

3. Saver JL, Carroll JD, Thaler DE, Smalling RW, MacDonald LA, Marks DS, et al. On behalf of the RESPECT investigators. Long-term outcomes of patent foramen ovale closure or medical therapy after stroke. $\mathrm{N}$ Engl J Med. 2017;377:1022-1032. DOI: 10.1056/ NEJMoa1610057.

4. Mojadidi MK, Elgendy AY, Elgendy IY, Mahmoud AN, Elbadawi A, Eshtehardi P, et al. Transcatheter patent foramen ovale closure after cryptogenic stroke: an updated meta-analysis of randomized trials. J Am Coll Cardiol Intv. 2017;10:2228-2230. DOI: 10.1016/j.jcin.2017.09.002.

5. Fanari Z, Hammami S, Hopkins JT. Successful percutaneous transcatheter patent foramen ovale closure through the right internal jugular vein using stiff amplatzer catheter with a reshaped tip. Del Med J. 2016;88:238-241. PMID: 28751787.
6. Welgraz P, Konarska-Kuszewska E, Zebik T, Kuszewski P, Drzewiecka-Gerber A, Motyka $M$, et al. Transcatheter closure of patent foramen ovale using the internal jugular venous approach. Postepy Kardiol Interwencyjnej 2014;10:123-127. DOI: 10.5114/ pwki.2014.43520.

7. Psutka SP, Leibovich BC. Management of inferior vena cava tumor thrombus in locally advanced renal cell carcinoma. Ther Adv Urol. 2015;7:216-229. DOI: 10.1177/1756287215576443.

8. Tanaka M, Fujimoto K, Okajima E, Tanaka N, Yoshida K, Hirao Y. Prognostic factors of renal cell carcinoma with extension into inferior vena cava. Int J Urol. 2008;:394-398. DOI: 10.1111/j.1442-2042.2008.02017.x.

9. Nishimura RA, Otto CM, Bonow RO, Carabello BA, Erwin JP 3rd, Guyton RA, et al. 2014 AHA/ACC guideline for the management of patients with valvular heart disease: a report of the American College of Cardiology/American Heart Association Task Force on Practice Guidelines. J Am Coll Cardiol. 2014;129:2440-2492. DOI: 10.1161/CIR.0000000000000029.

10. Vahanian A, Alfieri $O$, Andreotti F, Antunes MJ, Barón-Esquivias $\mathrm{G}$, Baumgartner $\mathrm{H}$, et al. Guidelines on the management of valvular heart disease (version 2012): The Joint Task Force on the Management of Valvular Heart Disease of the European Society of
Cardiology (ESC) and the European Association for Cardio-Thoracic Surgery (EACTS). European Heart Journal. 2012;33:24512496. DOI: 10.1714/1234.13659.

11. Epstein NE. Multidisciplinary in-hospital teams improve patient outcomes: A review. Surg Neurol Int. 2014;5(Supplement 7):S295-S303. DOI: https://doi. org/10.4103/2152-7806.139612. eCollection 2014.

12. Meissner I, Whisnant JP, Khandheria BK, Spittell PC, O'Fallon WM, Pascoe RD, et al. Prevalence of potential risk factors for stroke assessed by transesophageal echocardiography and carotid ultrasonography: the SPARC study. Stroke Prevention: Assessment of Risk in a Community. Mayo Clin Proce. 1999;74:862-869. PMID: 10488786

Cite this article as: Al Danaf $J$, Saidi A, Smith B, Tandar A. Patent Foramen Ovale Closure using Cardioform Occluder Device Through the Right Internal Jugular Vein for Primary Prevention (First in Man): Importance of a Multidisciplinary Team. Structural Heart Disease. 2019;5(2):43-47. DOI: https://doi. org/10.12945/j.jshd.2019.019.18 